\title{
DEMOCRACIA E OPINIÃO PÚBLICA NO RUMO DAS ELEIÇÕES ESTADUNIDENSES DE 2020
}

\author{
DEMOCRACY AND PUBLIC OPINION HEADING INTO THE 2020 US \\ ELECTIONS
}

DOI: $10.5380 / \operatorname{cg} . v 10 i 2.79488$

\author{
Nicole Tricarico ${ }^{2}$ \\ Theo Peixoto Scudellari3
}

\begin{abstract}
Resumo
O presente artigo traz como cerne central as relações entre o funcionamento da democracia e o papel da opinião pública sobre esta, tendo como panorama as eleições estadunidenses de 2020. Ou seja, há o objetivo central de se compreender os principais eventos que exerceram influência significativa sobre o pleito e, dessa forma, puderam "moldar" a opinião pública tanto para o voto em si como para a própria concepção geral sobre as principais características da democracia no país. A partir disso, torna-se possível a exploração dos principais efeitos da opinião pública - principalmente em um contexto polarizado como o da eleição de 2020 nos EUA sobre o processo eleitoral e sobre a democracia, entendendo seus principais efeitos e implicações. Para que tais objetivos possam ser cumpridos, são utilizadas obras de Robert Dahl sobre a democracia e sua conceituação, bem como artigos científicos, reportagens e matérias jornalísticas para embasamento empírico sobre os contextos envolvidos no país para as eleições. A análise efetuada e descrita nas seções seguintes contribui, portanto, para o entendimento sobre a relação intrínseca entre a sociedade e o sistema democrático em que se encontra, bem como as formas pelas quais os fenômenos influenciam no processo de mobilização social e esta, por sua vez, nas urnas. A opinião pública, portanto, é um fator não apenas de impacto midiático e apenas fundamentado a partir do voto, mas compreende também uma série de esferas que repercutem diretamente nos pilares estruturados como base da democracia.
\end{abstract}

Palavras-Chave: Democracia; Opinião Pública; Eleições EUA; Robert Dahl.

\begin{abstract}
This article has as its central core the relations between the functioning of democracy and the public opinion place on it, with the American elections in 2020 as an outlook. Therefore, there is the central objective of understanding the main events that had a significant influence on the election, and, in this way, they were able to "mold" public opinion both for the vote itself and for the general conception of the main characteristics of democracy in the country. From this, it becomes possible to explore the main effects of public opinion - mainly in a polarized context such as that of the 2020 election in the USA - on the electoral process and democracy, understanding its main effects and implications. To achieve these objectives, Robert Dahl's works on democracy and its conceptualization are used, as well as scientific articles, reports, and journalistic articles for empirical bases on the contexts involved in the country for the elections. The analysis carried out and described in the following sections, therefore, contributes to the understanding of the intrinsic relationship between society and the democratic system in which it finds itself, as well as how phenomena influence the process of
\end{abstract}

\footnotetext{
${ }^{1}$ Este artigo licenciado sob a Licença Creative Commons Attribution (CC BY 4.0), sendo permitido o compartilhamento com reconhecimento da autoria e publicação inicial nesta revista.

2 Bacharel em Relações Internacionais pela Universidade Estadual Paulista Júlio Mesquita Filho (UNESP) e mestranda em Ciência Política pela Universidade Federal do Paraná (UFPR). E-mail: nicoletricarico@hotmail.com. ORCID: https://orcid.org/0000-0002-6194-7236.

3 Bacharel em Relações Internacionais pela Universidade Estadual Paulista Júlio Mesquita Filho (UNESP) e mestrando em Ciências Sociais pela mesma instituição. E-mail: theoscudellari@gmail.com. ORCID: https://orcid.org/0000-0003-3514-2992.
} 
social mobilization and this, in turn, time, at the polls. Public opinion, therefore, is not only a factor with a media impact and is only based on the vote, but it also comprises a series of spheres that directly affect the pillars structured as the basis of democracy.

Keywords: Democracy; Public Opinion; USA elections; Robert Dahl.

"The notion that public opinion can and will decide all issues is in appearance very democratic. In practice it undermines and destroys democratic government. For when everyone is supposed to have a judgment about everything, nobody in fact is going to know much about anything” (LIPPMANN, 1922)

\section{INTRODUÇÃO}

É um fenômeno perceptível a reunião e associação de indivíduos a fim de atingir metas comuns. Chegar a consensos por meio da deliberação, debate e tomada de decisões políticas são a principal causa da formação dessas associações. O princípio mais básico que guia a organização é o igual peso dado à voz de cada associado, assegurando, assim, o direito de participação de todos no processo de tomada de decisão. Mas em que momento passamos a intitular essas associações de democráticas? Afinal, ao longo de toda a história, muitas organizações se autodeclararam democráticas mesmo apresentando formatos, constituições e dinâmicas distintas entre si.

Por muitas décadas, autores de diversas correntes de pensamento e posição política e social buscaram elencar regras e princípios que caracterizassem as sociedades democráticas, que nada mais são que as associações acima descritas. O americano Robert Dahl foi um desses autores, um teórico da chamada corrente pluralista e comportamentalista. Ele dedicou grande parte de seu trabalho ao estudo da democracia. Em suas obras, mesmo com o passar de anos e décadas, ele buscou responder quais os parâmetros e elementos fundamentais para a existência e funcionamento da democracia nas formas de governo contemporâneas. Em "Um prefácio à teoria democrática” (1956), ele dá os primeiros passos em direção a sua obra mais célebre "Poliarquia" (1971) e poucos anos depois publica "Sobre a democracia" (1974) com considerações e revisões aos seus estudos anteriores.

No presente artigo, pretende-se analisar brevemente os conceitos presentes nessas obras que fundamentam a argumentação de Dahl sobre a questão democrática, mais especificamente sobre a importância e peso da opinião pública nesse contexto. De forma que seja possível, ainda, analisar a influência exercida pela opinião pública nos rumos tomados ao longo das eleições estadunidenses de 2020.

Desse modo, a partir dos elementos supracitados e tendo em vista o arcabouço teórico oferecido por Robert Dahl, tem-se como objetivo central a compreensão do papel da opinião pública e das mobilizações sociais internas em diversos âmbitos no que tange ao desenvolvimento da democracia e do processo eleitoral nos Estados Unidos no ano de 2020, de maneira a destacar 
algumas particularidades que permitem a correlação dos conceitos a serem apresentados. Assim, além das principais obras de Dahl e outros autores que se debruçam sobre o estudo da democracia, os métodos e técnicas têm suas fontes nas matérias de veículos nacionais e internacionais, bem como artigos e textos que possam elucidar os processos que incidiram diretamente sobre o processo eleitoral estadunidense e sobre uma concepção de democracia que se pode atribuir à opinião pública do país em questão. Destarte, para que o referido objetivo possa ser atingido, busca-se a utilização de um método analítico-interpretativo a partir das fontes utilizadas, buscando estabelecer conexões práticas e teóricas estruturalmente embasadas pela construção argumentativa e de observação dos elementos contidos nas referências em questão.

A escolha de Robert Dahl como principal autor do referencial teórico se deu, fundamentalmente, pela dimensão de sua obra e dos conceitos utilizados para a compreensão da democracia e suas flexões entre os Estados, além de apresentar estudos importantes para a investigação democráticas dos Estados Unidos, país que promove poucas alterações no âmago de sua constituição e democracia. A atualidade de seus trabalhos, principalmente no que se refere aos parâmetros democráticos e conceitos para estudo desse sistema político, também possibilitou sua utilização para as bases teóricas do artigo. É evidente que outros autores também são utilizados para discutir essas questões, como Lijphart, Bobbio e Tilly, possibilitando maior clareza conceitual e, ao mesmo tempo, observar a atualidade dos referidos estudos sobre democracia.

Enquanto isso, as matérias jornalísticas e reportagens foram selecionadas a partir de pesquisa nas plataformas dos próprios veículos escolhidos pelos autores como fontes importantes para a função midiática do contexto mencionado, destacando-se os jornais El País, BBC, Folha de São Paulo, O Estado de São Paulo, CNN, NBC e The New York Times. Assim, tais plataformas ou jornais foram utilizados tanto pelo grande alcance como pelo impacto de seu conjunto de ferramentas informativas. Sendo assim, alguns tópicos foram pesquisados dentro de seus sites, buscando uma relação entre determinados temas e datas que fossem coerentes para o período objetivado no presente estudo. Assim, a partir da leitura e contextualização ampla acerca de alguns elementos, os tópicos foram divididos como apontados na próxima seção.

Para a análise acurada acerca da questão da opinião pública e não tornar o estudo muito difuso, buscou-se uma investigação em torno de aspectos mais voltados para a esfera interna dos EUA, mesmo que presentes também em escala global (como o caso da pandemia de COVID-19, analisando-se no artigo seus desdobramentos nos EUA). Nesse sentido, destaca-se que os movimentos sociais explorados, a partir de uma conceituação por Charles Tilly, foram selecionados no escopo doméstico dos Estados Unidos, compreendendo como as dinâmicas da política internamente foram importantes para a mobilização social, a construção de pensamentos - inclusive sobre as características e elementos centrais da democracia - que exerceram influência significativa sobre o pleito. Isso não significa, contudo, que apenas tópicos da política interna determinaram 
rumos para o processo, apenas buscou-se ressaltá-los no presente artigo para estabelecer uma coesão maior entre os elementos estudados.

Por fim, para que todo esse procedimento possa ser efetuado de maneira adequada e rigorosa no que diz respeito aos aspectos de ordem metodológica, o artigo será dividido em seções e subseções que possam explicitar a construção da argumentação e da análise que se realizou a partir do presente estudo. Inicialmente, realizar-se-á uma apresentação dos principais tópicos teóricos que merecem destaque para o embasamento. Posteriormente, uma retomada de eventos, movimentações e elementos práticos que marcaram o cenário eleitoral estadunidense em 2020 e suas influências para o pleito. Na sequência, busca-se utilizar ambas as discussões anteriores para compreender o cerne do objetivo e da pergunta proposta no artigo, de maneira que esta refere-se ao papel da opinião pública para o desempenho do sistema eleitoral e da própria concepção de democracia, entendendo o papel desses elementos para a construção dos fenômenos que circunscreveram as eleições e produziram consequências para os resultados observados.

\section{PANORAMA TEÓRICO}

\subsection{A DEMOCRACIA E AS INSTITUIÇÕES PARA ROBERT DAHL}

Ao revisitar e analisar as democracias mais próximas de sua realidade, como a democracia Madsoniana e Populista, Dahl busca compreender os critérios necessários para um modelo de democracia que ele vai conseguir desenvolver plenamente apenas em 1971 em "Poliarquia”. Mas é notável desde o início de suas formulações seu posicionamento dentro da corrente comportamentalista. Mas o que isso significa? Os comportamentalistas se preocupam com formulações baseadas na observação direta do mundo político concretamente observável. Podemos ver isso claramente quando ele afirma que: "nenhum estado jamais possuiu um governo que estivesse plenamente de acordo com os critérios de um processo democrático. É provável que isso não aconteça" (DAHL, 2001, pg. 53).

No que concerne à forma de governo democrático, Dahl acredita que o desenvolvimento do sistema político permitindo a oposição e rivalidade entre o governo e o restante de seus oponentes seria o aspecto fundamental da democratização. Argumentando que a característica fundamental da democracia é a contínua responsividade do governo às preferências de seus cidadãos, considerados politicamente iguais. Em Poliarquia (1971), Dahl estabelece dois parâmetros para analisar o grau de democracia presente em um regime político: (1) o grau de inclusão dos cidadãos no processo de escolha de seus líderes e governantes (a extensão do sufrágio); e (2) quantos grupos na sociedade competem pelo poder político (DAHL, 1997, p. 26). Dessa forma, pode-se considerar que quanto maiores são esses níveis, mais democrática é uma sociedade. Assim, a democracia em seu nível mais 
alto de desenvolvimento teria o direito ao voto atingido pela maior parte da população (sufrágio universal) e a competição pelo poder político envolvendo diversos grupos (partidos).

Como apontado anteriormente, para o autor, a democracia abrange muitos outros aspectos além desses dois, pois, “como (no meu entender) - afirma - nenhum sistema do mundo real é plenamente democratizado, prefiro chamar os sistemas mundiais reais que estão mais perto do canto superior direito de Poliarquias" (DAHL, 1997, p. 31). Dahl define a poliarquia, portanto, como um regime relativamente democratizado que foi substancialmente popularizado e liberalizado, ou seja, tornou-se fortemente inclusivo e amplamente aberto à contestação pública.

Dessa forma, o autor direciona toda a sua argumentação na busca de caracterizar o que ele chama de "uma verdadeira democracia”. Vale lembrar que a dimensão dessa análise está inserida no contexto de grandes nações soberanas, o que significa que parte-se de um objeto de estudo de grande escala. Para isso, Dahl propõe-se a responder a uma questão fundamental: que instituições políticas requer a democracia em grande escala? Em "Sobre a democracia" (1974) ele pontua seis instituições necessárias para o funcionamento de um regime democrático: funcionários eleitos; eleições livres, justas e frequentes; liberdade de expressão; fontes de informações diversificadas; autonomia para as associações; e cidadania inclusiva.

As instituições são, para Dahl, a base para a existência dos direitos e oportunidades mais fundamentais em uma sociedade. Sem elas não há democracia. E para sua existência e manutenção, elas dependem diretamente de uma cultura democrática.

Nas palavras do autor, "para manter suas instituições democráticas através de suas inevitáveis crises, um país necessitará de um corpo de normas, crenças e hábitos que forneçam apoio para as instituições em bons e maus momentos - uma cultura democrática que é transmitida de uma geração a outra” (DAHL, 2004, p. 7). Assim, para a análise proposta neste trabalho, o foco estará no peso que duas dessas seis instituições políticas possuem no funcionamento de um governo democrático: liberdade de expressão e fontes de informação diversificadas. Mas de forma alguma excluindo ou diminuindo a importância e peso que as demais possuem para qualquer análise de um sistema político.

Há uma crença consolidada no papel desempenhado por essas seis instituições e, de um modo geral, em todo o funcionamento da democracia, ainda mais em países de democracias consolidadas, como é o caso dos Estados Unidos. Porém, nas últimas décadas, vemos essas instituições experimentando adversidades e ataques, colocando em xeque toda a noção de democracia. Em um artigo publicado por Dahl denominado "Os sistemas políticos democráticos nos países avançados: êxitos e desafios" (2004), ele elenca cinco desafios enfrentados pelos países por todo o globo, das democracias mais jovens até as mais antigas e consolidadas. São eles: 1. O desafio de alcançar um equilíbrio entre as necessidades dos dois sistemas básicos - político e econômico; 2. O fato de que as organizações internacionais não são governadas democraticamente e provavelmente nunca o serão; 3. A diversidade cultural e as clivagens estão aumentando em quase todos os antigos 
países democráticos (devido principalmente à questão migratória); 4. O perigo de ataques terroristas; e 5. O problema da concorrência cívica.

Aproximando-nos assim do ponto nuclear do debate teórico proposto no presente trabalho, Dahl define o problema da concorrência cívica na seguinte passagem:

Ainda que fosse fácil sugerir padrões de informação e compreensão tão altos entre os cidadãos que seriam humanamente impossíveis de alcançar, poderíamos razoavelmente reduzir um pouco nossas pretensões e conformar-nos com o "cidadão adequado" ou "suficientemente bem-informado". Ele terá incentivos suficientemente fortes para obter um mínimo de conhecimento de seus próprios interesses e das opções políticas que mais provavelmente os promovam, bem como para agir em nome destas opções (DAHL, 2004, p. 9).

Os assuntos políticos, de políticas públicas a temas internacionais, tornam-se cada vez mais complexos e distantes das experiências diretas e preocupações mais imediatas da grande maioria dos cidadãos. Consequentemente, diversos estudos revelam que, em todos os países democráticos, até mesmo nas mais antigas democracias, a grande maioria dos cidadãos possui uma compreensão bastante deficiente sobre política, suas instituições, seu papel como cidadão e até mesmo seus direitos mais básicos.

\subsection{OPINIÃO PÚBLICA}

A opinião tem uma história tão antiga quanto a da humanidade, tanto nas sociedades mais primitivas quanto nas mais avançadas e desenvolvidas. A linguagem está diretamente ligada à forma como os seres humanos vivenciam o mundo que os cerca e é por meio dela que formulam e exprimem suas opiniões a partir do contato sensorial direto ou por palavras transmitidas por outros humanos.

O que a maioria dos teóricos faz é um prematuro salto da opinião para a opinião pública. De forma conceitual, há realmente um pequeno passo que separa a opinião individual da opinião pública, porém, historicamente, esse é um passo gigantesco porque, até o século XIX, o termo "opinião pública" era pouco relevante na análise política. Por conseguinte, nasce uma "crença no homem comum" (FRIEDRICH, 1942 in LOWI, THEODORE \& CALISE, 2010) a qual emerge com o propósito de criar um lugar próprio de pertencimento para a opinião pública nos assuntos governamentais e um lugar para os indivíduos comuns na história.

Historicamente, o advento da opinião pública nasce a partir de profundas mudanças em toda a estrutura do aparelho governamental onde se estrutura a esfera pública, assim como do surgimento de uma nova classe de indivíduos determinados a influenciar a esfera pública tanto por meio do debate quando críticas ao funcionamento de todo o sistema (HABERMAS, 1989 in LOWI, THEODORE \& CALISE, 2010, p. 163). Um movimento que decorreu do nascimento de uma classe média esclarecida, fato que caminhou lado a lado à conquista de sua autonomia econômica (o que os europeus chamavam de predominância burguesa e os americanos de emancipação do homem 
comum). Nas duas subseções seguintes, o foco recairá numa análise sucinta dos dois quadrantes esquerdos dispostos na Imagem 1, retirada do artigo de Lowi, Theodore e Calise (2010), escolhidos com base no direcionamento do trabalho proposto neste artigo.

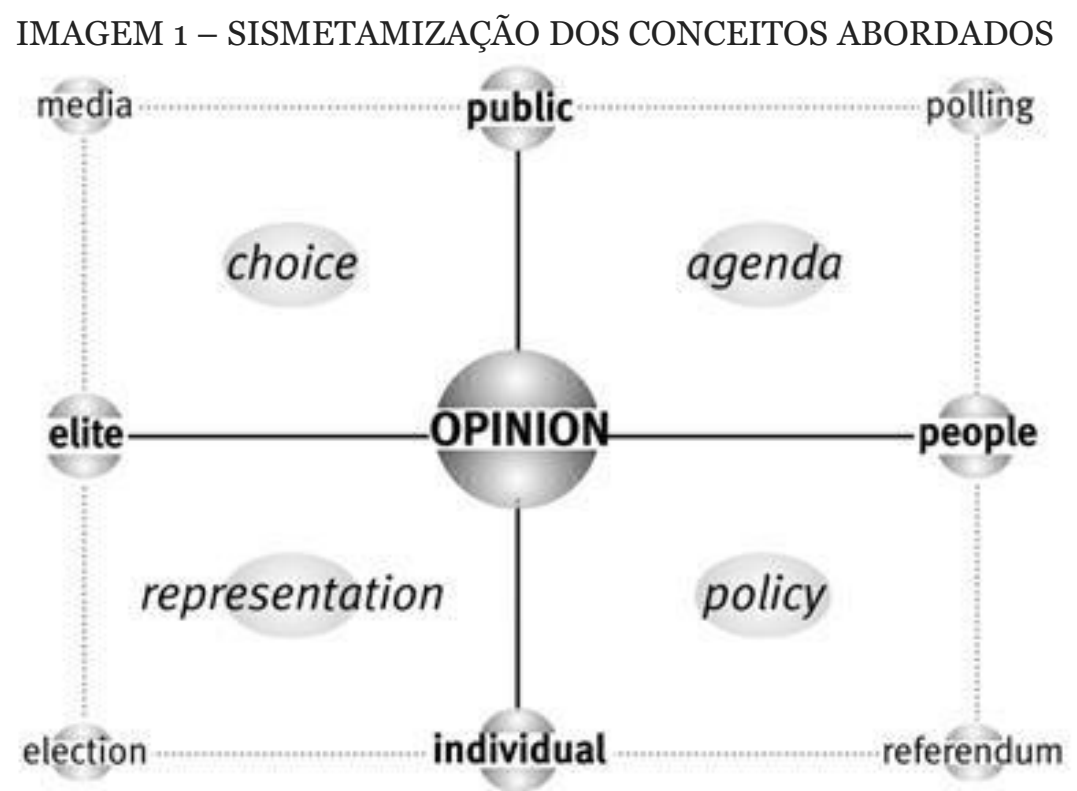

FONTE: Lowi, Theodore e Calise (2010).

2.2.1. O quadrante superior esquerdo

No primeiro quadrante de análise, observável na Imagem 2, é possível observar dois fatoreschave fundamentais para o desenvolvimento e consolidação da opinião pública, são eles: 1. Uma mídia forte e pluralista como fonte de informações; e 2. A escolha racional dos indivíduos como parâmetro básico de um julgamento livre e responsável.

\section{IMAGEM 2 - QUADRANTE SUPERIOR ESQUERDO: ESCOLHA}

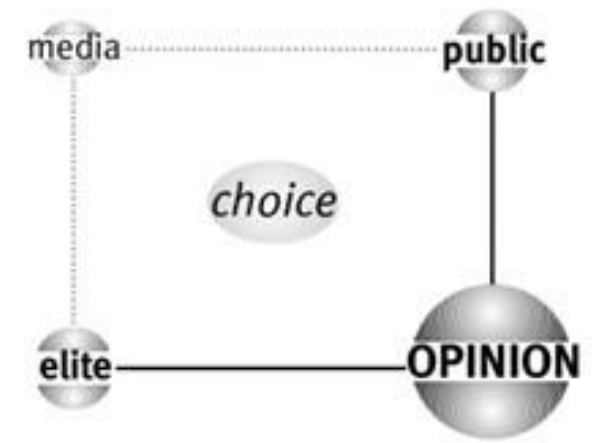

FONTE: Lowi, Theodore e Calise (2010).

O papel de uma imprensa independente e responsável como um canal de comunicação confiável do discurso público foi por muito tempo subestimado. Foi somente na "era do esclarecimento" que a difusão de notícias dominou a esfera pública, e o alcance que as informações 
tomaram com o passar das décadas desencadeou uma grande mudança na abordagem das próprias autoridades públicas.

Uma relação estreita foi estabelecida ao longo do tempo entre a propaganda política e a difusão da imprensa, tal fato tornou-se um dos traços mais fundamentais para o desenvolvimento da democracia dos Estados Unidos. "Ao atingir um público de massa por meio de canais abertamente políticos, a opinião pública cria as condições para a auto realização de sua missão normativa: a mobilização generalizada de cidadãos informados para discutir abertamente e avaliar a gestão dos assuntos governamentais" (Jacobs e Shapiro 1996 in LOWI \& CALISE, 2010, p. 164). Consequentemente este se torna o ponto em que a opinião pública inevitavelmente caminha para novas direções (quadrantes), como, por exemplo, a representação.

\subsubsection{O quadrante inferior esquerdo}

Ao analisar a Imagem 3, pode-se considerar um equívoco concluir que o direito ao voto e participação de um governo representativo tenha sido o resultado de um longo período de reivindicações e lutas, no qual o povo exigiu seu direito de representação e participação eleitoral. Na realidade, tais demandas não estavam ausentes, mas a extensão do sufrágio e dos mecanismos formais de representação ocorreram gradativamente depois que a opinião pública alcançou certa posição de relevância nos negócios públicos e as pessoas possuíam maior influência nas decisões políticas.

\section{IMAGEM 3 - QUADRANTE INFERIOR ESQUERDO: REPRESENTAÇÃO}

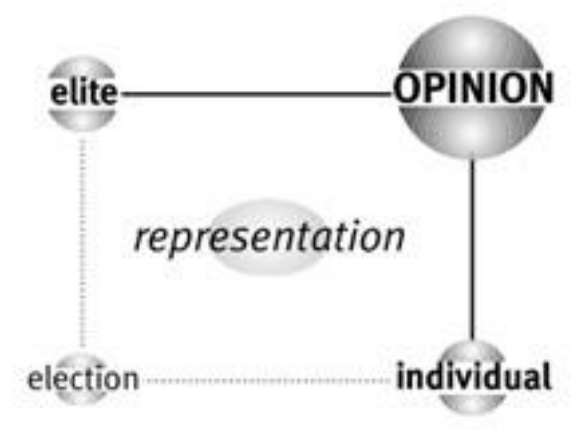

FONTE: Lowi, Theodore e Calise (2010).

Com relação à experiência americana, Schattschneider, em sua obra "The Semisovereign People" (1960), traz um ponto fundamental ao argumentar acerca da dificuldade que é, para os norte-americanos, crer nesse processo histórico acima descrito, pelo fato de possuírem uma visão desesperadamente romântica da história da própria democracia, que sempre atribuiu um significado revolucionário e idealizado de todo o processo de extensão do sufrágio (SCHATTSCHENEIDER, 1960). 


\subsection{OPINIÃO PÚBLICA}

Como apontado na introdução do presente artigo, os movimentos sociais e mobilizações colocam-se como um aspecto central para a compreensão da conjuntura eleitoral dos EUA em 2020, marcando posições e explorando dinâmicas da expressão da opinião pública. Nesse sentido, buscase compreender, conceitualmente, o que são os movimentos sociais em sua forma contemporânea e quais os atributos centrais que caracterizam sua relevância na esfera política de determinado contexto. Além disso, auxilia na delimitação dos tópicos selecionados para análise, compreendendo o impacto dos movimentos em questão e como eles fomentam o debate acerca da opinião pública no que se refere ao pleito eleitoral e sobre a própria democracia.

Charles Tilly é considerado como um dos principais ícones da sociologia do século XX, trabalhando com diversos temas, dentre eles a compreensão acerca dos movimentos sociais, utilizando-se de uma lógica estruturalista, rompendo com perspectivas deterministas e economicistas (ALONSO, 2012). Assim, utilizava-se de elementos históricos para compreender o papel da sociologia na compreensão dos movimentos sociais - a exemplo de sua obra As Sociology Meets History (1981), entendendo-os como fenômenos atrelados à esfera política.

Tilly (2009) compreende que há uma variedade de apropriações e definições acerca da ideia de movimentos sociais - não que ele as considere incorretas, apenas busca apresentar uma visão com parâmetros e valores importantes para a compreensão dos elementos político-sociais envolvidos no contexto estudado, de maneira a se reduzir os movimentos sociais como algo uniforme e voltado apenas para um grupo ou para as redes que auxiliam na condução dos mecanismos de reivindicação.

Desse modo, há uma análise do referido autor compreendendo que os movimentos sociais, inicialmente, estão voltados para elementos atrelados ao escopo político (ALONSO, 2012), ou seja, apresentam pautas, características, alvos e atores que estão inseridos no meio político e que objetivam mudanças por esse meio, condensando uma gama de diálogos e reivindicações para uma necessidade de transformação. Na compreensão de Tilly, voltada para a história e compreensão da transformação dos fenômenos historicamente, os movimentos sociais, da forma como os interpreta, passaram a se desenvolver no fim do século XVIII e início do XIX, trazendo consigo características importantes para uma definição como movimento social, além das já mencionadas anteriormente. Assim, há uma dinâmica histórica dos movimentos sociais que deve ser considerada, levando em conta que cada contexto político influencia nessas formas de organização. O movimento social, portanto, apresenta características únicas que o diferem de outras formas de organização justamente por essa transformação a partir de cada realidade e dos elementos políticos intrínsecos em sua dinâmica. 
Tendo tais elementos em vista, Tilly (2009) compreende que os movimentos sociais trazem fundamentos importantes para sua conceituação e, portanto, sua compreensão em determinados momentos históricos. Assim, ele pontua que:

Esse complexo político combinou três elementos: 1) campanhas de reivindicações coletivas dirigidas a autoridades-alvo; 2) um conjunto de empreendimentos reivindicativos, incluindo associações com finalidades específicas, reuniões públicas, declarações à imprensa e demonstrações; 3) representações públicas de valor, unidade, números e comprometimento referentes à causa. A esse complexo historicamente específico denomino movimento social. (TILLY, 2009).

Observa-se, então, que a compreensão do autor acerca de movimentos sociais é extremamente importante para a caracterização de determinadas mobilizações de maneira a objetivar determinados fins - mudanças sociais, majoritariamente - a partir da política, envolvendoa e criando meios para que ela esteja presente nos procedimentos. Portanto a relevância desse debate se ressalta no presente trabalho. A utilização da unidade - como materiais em comum, vestimentas, símbolos etc. -, por exemplo, coloca-se presente em movimentos mencionados no decorrer do estudo, possibilitando uma melhor circunscrição conceitual e teórica.

Os movimentos sociais, por fim, envolvem, atreladas às reivindicações por mudanças e pela expressão de determinadas necessidades - vinculadas a um escopo político como participante ou como meio -, a conexão entre grupos com determinados anseios e a valorização da identidade entre valores, concepções e entendimentos no que se refere aos princípios e aspectos basilares da vida social.

\section{AS ELEIÇÕES DE 2020 NOS EUA: PRINCIPAIS VARIÁVEIS, FENÔMENOS E IMPLICAÇÕES}

Nesta seção, busca-se, então, apresentar fatos e acontecimentos, bem como o contexto em que estavam inseridos em relação ao processo eleitoral, que foram determinantes para a situação de polaridade política na sociedade estadunidense e para a derrota de Trump. Assim, os tópicos elencados buscam descrever as formas como as ações políticas reverberaram com relação a cada um dos acontecimentos e quais as observações que podem ser feitas acerca disso. As descrições e análises embasadas a partir das fontes - artigos, livros, noticiários, jornais internacionais - buscam abstrair os juízos de valor e elaborar uma argumentação pautada a partir dos objetivos que foram descritos anteriormente, quais sejam: a compreensão do contexto do pleito eleitoral nacional nos Estados Unidos e como a opinião pública - marcada pela polarização, como observado - pode ser determinante para a democracia e seu funcionamento, bem como do próprio sistema eleitoral (o qual se materializa como um atributo essencial desse sistema democrático). Isto é, busca-se enfatizar a 
maneira como tais acontecimentos reverberaram no pleito e quais suas implicações para a democracia, entendendo como as polarizações influenciaram seu funcionamento e a concepção social sobre sua efetividade.

\subsection{O GOVERNO DE DONALD TRUMP E A BUSCA PELA REELEIÇÃO}

Chegado o ano de 2020, a política dos EUA enfatizou seus olhares para o processo eleitoral (para a presidência e casas legislativas), que ocorreria no fim do ano, atribuindo significativa atenção para este em função da polarização política que se observava na sociedade estadunidense. $O$ presidente em exercício, Donald Trump, do Partido Republicano, buscava sua reeleição após quatro anos à frente da Casa Branca, tendo em vista suas promessas de recuperação econômica fortalecido sua participação no pleito, bem como os discursos de ordem mais conservadora, atribuindo um papel de centralidade aos Estados Unidos, e a busca por um maior protecionismo e valorização do unilateralismo nas relações internacionais - o que poderia ser observado a partir de muitos dos slogans que marcaram sua disputa em 2016 e os anos de seu governo, como o "America First",

"Make America Great Again”, entre outros (PECEQUILO; MAGNOTA, 2020; GONÇALVES; TEIXEIRA, 2019).

Essa política de Trump obteve diversas interpretações e análises por parte dos estudiosos e demais políticos, de maneira que nunca perdeu de vista o objetivo de manutenção dos EUA como potência central do sistema internacional, o que Barry Posen

(2018) chamou de "hegemonia iliberal", ou seja, Donald Trump promoveu suas ações buscando reduzir a participação cooperativa e multilateral, traçando mecanismos que colocassem os interesses dos EUA à frente e pudessem consolidar o papel hegemônico global, principalmente nos quesitos militar e econômico (VINHA, 2017). Muitos desses tópicos envolvendo organismos e agendas internacionais serão destacados com maior ênfase doravante. O ponto central a se destacar no presente tópico é demonstrar que a política de Trump obteve, no decorrer de seu mandato, uma grande díade entre aprovação e reprovação, o que deixava um estado de incerteza quanto às eleições de novembro de 2020, principalmente antes de se ter o conhecimento do candidato que seria escolhido pelo Partido Democrata para concorrer no pleito. Entende-se, então, que um dos elementos centrais que marcaram a administração de Trump foi a busca por um sentimento de filiação nacional, contestando-se, a partir dessa lógica, o próprio sistema como se configura inclusive a partir da própria política dos Estados Unidos após a Segunda Guerra Mundial - e a forma como a política internacional se dinamizava (OLIVER; RAHN, 2016). O alinhamento de Trump a essas questões, como mencionado, dividiu opiniões e tornou o cenário estadunidense incerto no que se refere à continuidade ou não de seu governo após as eleições. Além da forma como conduzia suas ações políticas - de acordo com os princípios e tópicos mencionados anteriormente -, outros fatores podem ser observados e analisados como de influência significativa para todo o contexto que 
envolveu o processo eleitoral, bem como seu resultado e os desdobramentos posteriores a este (PECEQUILO, 2020). Assim, nos subtópicos subsequentes serão analisadas brevemente outras questões que se somam à condução da política de Trump, compreendendo a divisão opinativa que assolou o eleitorado estadunidense.

\subsection{MOVIMENTOS ANTIRRACISTAS E BLACK LIVES MATTER}

Tratando-se de política e sociedade, um fator que pode ser descrito como importante referese aos direitos civis e as formas de expressão que estes alcançam em um contexto democrático, tendo-se em vista a ponderação de Dahl (2001) sobre os direitos das minorias e importância destes para a existência da democracia. Sendo assim, compreende-se que os movimentos antirracistas eclodiram nos Estados Unidos após o assassinato de George Floyd por um policial. A importância desses protestos para a tratativa do presente artigo amplia-se a partir da forma que se analisa a atuação do governo do país com relação aos reclames dos grupos que participavam dos atos por todo o país - e que adquiriram alcance internacional.

O governo de Donald Trump considerou os movimentos antirracistas - com destaque para o grupo intitulado Black Lives Matter - como violentos, de modo que buscaria as ações e alternativas necessárias para que a ordem pudesse ser restabelecida no país, o que culminou em confrontos dos manifestantes com a polícia e uma série de prisões. A ação foi vista tanto por manifestantes como por parte da mídia como arbitrária, de maneira que se argumentava, por parte desses grupos, que essas respostas apenas reforçavam o racismo presente na sociedade estadunidense. Dessa forma, os protestos, tanto presenciais como pelas redes sociais, ganhavam cada vez mais força, obtendo apoio, inclusive, do candidato do Partido Democrata, Joe Biden, até mesmo nos próprios debates entre os candidatos nas semanas anteriores à eleição.

Nota-se, desse modo, que a questão dos direitos civis e das minorias vem sendo um elemento crucial para a avaliação de determinado conjunto de políticas, discursos e ações de governantes e demais envolvidos na lógica do poder. E o alcance que os movimentos antirracistas atingiram em 2020 foi claramente notável, com a internet sendo um mecanismo de ampliação dessa abrangência. Isto é, a forma como determinado governo atua diante dos direitos civis e suas mobilizações é determinante para o pensamento social acerca dos indivíduos que dele fazem parte, seja apoiando mais ou apresentando maior rejeição - no caso dos EUA, ampliou a polarização, principalmente pelo fato de Donald Trump não estar alinhado com as políticas mais progressistas dos direitos civis (INATOMI, 2019). Somando-se isso com o supracitado alcance dos movimentos, passa a haver uma ofuscação maior da popularidade do presidente, o que se concretizou nas eleições apesar da quantidade significativa de votos recebidos por ele.

Entende-se, portanto, que este tópico se apresenta como importante na análise do processo eleitoral de 2020 nos EUA e da própria compreensão de democracia de parte da população civil. 
Primeiramente, como já apontado, os movimentos apresentaram amplo alcance pela causa do antirracismo, despertando empatia e até mesmo o apoio de muitos veículos midiáticos de impacto. Todos esses elementos geram grandes engajamentos. Enquanto isso, por outro lado, há o grupo dos que não simpatizavam com as mobilizações e chegavam a caracterizá-las como terrorismo ou atos criminosos - como o próprio presidente Donald Trump chegou a sugerir em alguns momentos (chamando de "terrorismo doméstico"). Desse modo, portanto, acreditava-se que a democracia poderia significar a satisfação das necessidades de direitos das minorias, como era o caso do movimento, como também, para o outro lado, significaria ordem ou a busca pela identidade americana como os próprios slogans "America First" ou "Make America Great Again" conotam de maneira mais implícita (PECEQUILO, 2020; INATOMI, 2019).

\subsection{A PANDEMIA DE COVID-19}

Em 2020, o mundo foi impactado por um contexto devastador e de grandes dificuldades a níveis internacional e doméstico: a pandemia do novo coronavírus, o SarsCov-2, causador da COVID-19. Em janeiro, já estava ligado um alerta para o crescimento de casos na China e os primeiros dados divulgados de transmissão para outros países, crescendo em níveis consideráveis. Com o alcance da disseminação e o consequente risco de aumento de mortes, a OMS declarou em março a classificação da situação como uma pandemia.

Desse modo, a partir do crescimento da contaminação e do risco de complicações para os sistemas de saúde, observou-se as complexidades de condução política com relação à pandemia, principalmente no início desta, uma vez que, tratando-se de um vírus novo e com pouco tempo para análise científica, não havia grandes consensos sobre a forma de procedimento. Posteriormente, alicerçado aos estudos sobre a forma de disseminação do vírus, definiu-se - com apoio da OMS - o distanciamento social e a quarentena, bem como o uso de máscaras e higienização frequente, como métodos para conter a pandemia a curto prazo até o desenvolvimento das vacinas ou descoberta de medicamentos eficazes no tratamento para a COVID-19.

Entretanto, além das dificuldades na esfera sanitária, havia os problemas que se desencadeavam na economia, principalmente pela redução das atividades e da própria circulação tanto de mercadorias, pessoas e capital. Muitos países obtiveram sucesso nas medidas de contenção, fechando fronteiras e restringindo a circulação interna, como é o caso da Nova Zelândia. Nos EUA, o presidente Donald Trump colocou-se, desde o início, em uma posição contrária às medidas de distanciamento social e de minimização do vírus, desconsiderando sua gravidade - principalmente com a ampliação do número de contágios - e os impactos em consequência (FERREIRA et al., 2021). Essa estratégia foi vista por veículos de comunicação e estudiosos como mais um reflexo do negacionismo científico do presidente estadunidense, assim como no que se refere às questões climáticas (BUSS; ALCAZAR, 2020). 
Essa abordagem diante da gravidade e complexidade da pandemia da COVID-19 trouxe alguns desdobramentos importantes para a caminhada de Trump em busca da reeleição. A minimização do vírus, a indicação de medicamentos ineficazes e a contrariedade quanto às medidas de isolamento social fizeram emergir uma imagem de descontrole da situação, principalmente quando os Estados Unidos se tornavam o epicentro da doença no mundo, com maior número de contaminados e de óbitos. Assim, uma atuação voltada para um viés populista acabava por dividir a sociedade estadunidense, fazendo com que parte dela - os principais apoiadores - agissem em conformidade com as contrariedades de Trump às medidas de isolamento (MORAIS; COSTA; BERNARDI, 2020). Mesmo com esse apoio de parte de seu eleitorado, a popularidade de Donald Trump vinha sendo abalada com o avanço das consequências - principalmente o número de mortes - da pandemia, na medida em que seu opositor, Joe Biden, tratava do tema com cautela.

Além desses elementos, a dificuldade de aplicação das políticas econômicas pelo contexto pandêmico também colocara em xeque o possível favoritismo de Donald Trump. A própria manutenção da atividade econômica em detrimento do isolamento social era uma das justificativas dele para a contrariedade dessas últimas, mesmo que estudos - como um publicado pelo Banco Interamericano de Desenvolvimento - apontando que, quanto mais cedo a contenção do vírus fosse bem sucedida, melhor seria para a recuperação econômica, uma vez que os danos não se estenderiam a longo prazo, atrelando-se medidas fiscais rígidas para que a crise não tomasse uma forma cada vez mais grave.

Apreende-se, então, que a pandemia de COVID-19 trouxe ainda mais dificuldade para Donald Trump buscar a eleição e fez com que a sociedade observasse o contexto pelo qual os EUA vinham passando, determinando uma mudança nos rumos do governo para que houvesse perspectivas diferentes na Casa Branca daquelas do então presidente (BACCINI; BRODEUR; WEYMOUTH, 2020). A população passou a entender a importância de participar do pleito eleitoral - o que pode ser um dos principais motivos para a participação recorde na eleição de 2020 - e da atuação no sistema democrático. A própria pandemia e os riscos das aglomerações sociais fizeram com que a votação por correspondência - já existente em eleições anteriores - fosse ainda mais utilizada, principalmente por aqueles que se colocavam contrários às políticas de Trump, como os próprios resultados eleitorais demonstraram (muitos dos votos destinados ao eleito Joe Biden foram por correspondência). Assim, entende-se a pandemia como um dos elementos centrais determinantes para o resultado das eleições e das manifestações populares contra a reeleição de Donald Trump.

\subsection{AS FAKE NEWS E A DESMORALIZAÇÃO DO SISTEMA ELEITORAL DOS ESTADOS UNIDOS}

Como se pôde observar, a partir dos elementos mencionados nos subtópicos anteriores, o processo eleitoral dos EUA obteve influência de diversos outros eventos - de forma que apenas 
alguns foram destacados no presente artigo -, principalmente no que se refere à opinião pública, sendo esta uma das bases tanto para a legitimidade e reconhecimento das ações políticas (o que pode se materializar a partir do voto e do respaldo positivo) como para a própria sustentação do sistema democrático, isto é, a opinião pública se estabelece como um de seus pilares fundamentais, sendo até mesmo ponto determinante para a tomada de decisão política (SHAPIRO, 2011). Destarte, observava-se de antemão que seria uma disputa acirrada nas urnas entre Donald Trump e seu rival democrata Joe Biden.

Nesse cenário, desde meados do ano de 2020, o então presidente Trump "alertava" seus eleitores e toda a sociedade dos EUA para uma possível tentativa de fraude eleitoral, de maneira que ele seria o favorito para vencer e, caso isso não ocorresse, deveria haver uma observação acerca dos procedimentos circunscritos na organização eleitoral. As alegações foram vistas como infundadas e sem embasamento, tanto que algumas redes sociais, como o Twitter principalmente, alertaram sobre a falseabilidade das informações apresentadas pelo presidente. Entretanto, essa perspectiva já estava fazendo parte do ideário geral da população, de modo que muitos aderiram à retórica de que as eleições estavam tomando um caminho de fraude, principalmente os votos que seriam realizados por correspondência - o que iria se ampliar nesse ano por conta da pandemia. Essas afirmações apresentadas pela mídia internacional como fake news - fundamentaram uma descrença social acerca do próprio sistema eleitoral estadunidense, vigente há um longo tempo, e, consequentemente, da democracia (LEE, 2019).

Já nas eleições de 2016, as fake news fizeram parte do processo eleitoral, de maneira que estas se configuram como todo um processo de mapeamento do eleitorado e dos indivíduos em geral a partir das bases de dados online para determinar diretrizes de desinformação, formas de ganhar votos dos indecisos e maneiras de tornar as informações falsas cada vez mais próximas da aparência da verdade (BAPTISTA; AGUIAR, 2020).

A lógica da utilização das informações falsas e da busca pela chamada "pós-verdade" é um elemento bastante comum entre governos e figuras populistas, de maneira que se objetiva a aproximação com determinado grupo social que aceite tais informações e dados, ampliando a base de disseminação destas e garantindo maior espaço e popularidade, bem como conseguindo respaldo político e eleitoral (BERNARDI; COSTA, 2020).

Essa questão, aliada a toda influência que os demais acontecimentos trouxeram para as eleições de 2020, é uma das bases para se compreender o papel da opinião pública, uma vez que as alegações de fraude e a própria descrença no sistema passaram a crescer exponencialmente, principalmente após a virada de votos para Joe Biden em alguns estados tidos como importantes. Trump, até a posse de Biden, não havia reconhecido a derrota e ainda insistia no discurso voltado para a ocorrência de fraude eleitoreira. Mesmo após as eleições, ainda havia um clima, por parte dos apoiadores do republicano, de que o sistema havia se corrompido, de que não "havia democracia" na eleição de Joe Biden, uma vez que as eleições não estariam representando os verdadeiros anseios do 
povo. As mobilizações cresciam de maneira exponencial contra o resultado das urnas, com indicações seguidas de fraude, mas sem as correspondentes apresentações de provas acerca delas.

O grande ápice desses movimentos, alegações e desmoralização acerca da democracia estadunidense ocorreu no dia 6 de janeiro de 2021, no dia em que o Congresso dos EUA deveria confirmar a vitória de Joe Biden nas eleições, cujo evento coloca-se historicamente como uma mera formalidade. Antes da sessão, Trump solicitava, de maneira ilegal, que o vice-presidente, Mike Pence, um dos líderes do Congresso, não reconhecesse a vitória do democrata. Como isso não estava em pauta até mesmo pela legalidade de todo o processo, um grupo de apoiadores de Trump marchou rumo ao Capitólio - sede do Congresso estadunidense - com vias a mudar o resultado, com cartazes sugerindo que o verdadeiro presidente era Trump e que os parlamentares deveriam alterar os resultados - os quais seriam fraudados, nessas argumentações. A marcha para o Capitólio deixou de ser pacífica, tornando-se uma invasão que deixou diversos feridos, presos e quatro mortos. Especialistas e estudiosos afirmaram que o movimento poderia até mesmo ser visto como uma falha tentativa de golpe. A ação gerou repercussão e preocupação internacionalmente e inclusive levou a novos pedidos de impeachment de Trump - os quais foram aceitos pela Câmara dos Deputados - por incitação da violência, principalmente por meio de suas redes sociais, as quais, vale ressaltar, foram desativadas por violação dos padrões de uso e disseminação de informações falsas.

\section{O IMPACTO DA OPINIÃo PÚBLICA PARA AS ELEIÇÕES ESTADUNIDENSES DE 2020}

Como descrito anteriormente, o objetivo de relacionar o conceito de opinião pública e seu papel direto no sistema democrático permeou os estudos que levaram ao presente artigo, de maneira que os tópicos anteriores buscaram uma construção dessa argumentação a partir tanto dos elementos teóricos quanto dos fenômenos propriamente ditos, observando-se a particularidade de cada um deles e suas determinações para o processo eleitoral dos EUA (sendo este um dos elementos que elucida o ideal de democracia), e, consequentemente, para o conceito de democracia que se aplica ao país, principalmente em conformidade com as ponderações de Robert Dahl. Assim, podem ser discutidos com maior profundidade os elementos mencionados na seção anterior em união com o escopo teórico previamente apresentado, determinando os objetivos gerais do presente artigo, ou seja, o debate a partir da união de ambos permite que as principais conclusões e atribuições possam ser realizadas.

Observou-se que o contexto da eleição por si só já era complexo, com Donald Trump buscando a reeleição e ganhando a força de um eleitorado, mas, ao mesmo tempo, ampliando as polarizações políticas no país, o que se aprofunda ainda mais em se tratando de um sistema majoritário ("the winner takes it all"). Desse modo, o pleito representaria um elemento importante 
para a democracia estadunidense, de maneira que a escolha demonstraria o impacto dos eventos sobre sua opinião e mobilização. Importante ressaltar que essa mobilização se deu tanto na forma de movimentos como, e principalmente, pelas mídias on-line, as quais viram a interação e polarização política crescerem exponencialmente.

Essa questão ficou nítida nos movimentos antirracistas e do grupo Black Lives Matter, os quais atingiram um grande alcance nas redes midiáticas e sociais, estabelecendo em voga o objetivo central da mobilização, transmitindo a mensagem para diversos interlocutores, ampliando as relações e engajamentos, sendo considerados alguns dos maiores da história do país, de acordo com o New York Times. Portanto constata-se que a busca pela opinião pública em torno de uma causa e de um tema, como neste caso mencionado, é importante, pois sempre há desdobramentos no âmbito político, principalmente por meio do voto. A amplitude dos movimentos antirracistas foi internacional, levando as mídias a divulgar cada vez mais os elementos principais daquele fenômeno, obtendo, inclusive, apoio do candidato democrata Joe Biden, enquanto, por outro lado, Donald Trump chegou a caracterizá-los como terrorismo doméstico, como já mencionado. Com o grande alcance dos movimentos e a já existente polarização política, tendeu-se a criar um apoio ao candidato democrata os indivíduos que concordassem, apoiassem e se identificassem com a causa, enquanto o eleitorado mais sólido de Trump permaneceu em posição crítica a eles. Em função dessa dissensão política e a intensificação das manifestações de opinião pública sobre determinado evento, compreende-se seu papel determinante para o pleito eleitoral com vitória democrata e, ainda, sobre como cada parte envolvida nesse dualismo observava as mobilizações - com um lado entendendo seu direito de manifestação em prol dos direitos civis e o outro em posição de contrariedade alegando ações criminosas e vandalismo -, o que influía diretamente sobre a concepção de democracia que cada "lado" passava a desenvolver em seu espectro argumentativo, muito por conta da própria consonância com suas experiências e convicções políticas, as quais são determinantes para a interpretação dos fatos e suas características centrais e os consequentes posicionamentos (BAPTISTA; AGUIAR, 2020).

Isto posto, deve-se observar que não apenas essas mobilizações presenciais e online exerceram um papel central para a manifestação ampla da opinião pública em torno da democracia, mas a própria forma como outras questões eram apresentadas por veículos de informação, com papel fundamental - para análise e objetivos do presente artigo - das fake news ou informações falsas, uma vez que, de forma similar que o movimento antirracista, estas faziam parte do arcabouço por meio do qual o eleitorado estabeleceria seu processo interpretativo da realidade e dos fatos atinentes à sociedade estadunidense. Desse modo, a velocidade com a qual as informações falsas se disseminavam foi determinante para a criação de um imaginário de que a democracia americana estaria passando por um momento delicada em que um dos seus pilares - a eleição democrática estaria sob alvo de fraude, por exemplo, ampliando ainda mais as dissonâncias na opinião pública na esfera política, além de uma desmoralização sobre o sistema democrático estadunidense, a qual 
teve como seu grande ápice na invasão ao Capitólio em 6 de janeiro deste ano, dia em que o congresso certificaria a vitória de Joe Biden, de maneira que a ação foi justificada como um ato para que a democracia não fosse atentada com fraude e mentiras (como os próprios cartazes dos manifestantes sugeriam). Esse fato é apenas uma das consequências - das mais graves - do impacto das informações falsas em consonância com a mobilização em torno da opinião pública (BERNARDI; COSTA, 2020). Assim, esse tipo de informação, utilizada em todo o período eleitoral, foi importante para conduzir a opinião pública a uma concepção de que a democracia estaria sendo afetada e destruída aos poucos, o que se intensificou com a vitória de Biden no pleito. Conclui-se, nesse sentido, que a disseminação desse tipo de informação é algo que adentra com potência significativa nos conceitos políticos dos indivíduos, apresentando tópicos que mascaram a verdade em prol da adesão retórica (BAPTISTA; AGUIAR, 2020). Deve-se ressaltar que cada um desses fenômenos (as fake news, a invasão do Capitólio em si etc.) são temas bem mais complexos e que podem ser objetos específicos de estudos futuros, ampliando o escopo e o alcance teórico-prático do presente artigo.

Com relação à posição tomada por Donald Trump acerca da epidemia e crise sanitária por ela provocada, é possível compreender que está diretamente correlacionada à sua não reeleição no pleito de 2020. Sua forma de lidar com a pandemia da COVID-19 foi considerada por muitos estudiosos e pesquisadores como um evidente sintoma de um governo que desde o seu início negou a ciência, desde questões climáticas e sociais no início de seu exercício como presidente até sua forma de lidar com uma crise sanitária global. Como apontado anteriormente pelo panorama do cenário político que envolveu a reeleição e o pleito de 2020, a pandemia envolveu muito mais que somente uma doença altamente contagiosa, ela colocou à prova o funcionamento das estruturas e instituições das nações por todo o globo. E a maneira como Trump lidou com toda a conjuntura, desde a indicação de medicamentos ineficazes (com divulgação aliada com a disseminação de fake news) até a falta de seriedade com relação às medidas de isolamento social transpareceu uma imagem de completo descontrole da situação. Provavelmente a sua posição diante da pandemia foi o estopim para a desaprovação de seu governo perante a população estadunidense, mas também no mundo todo.

Por fim, pode-se compreender que a atuação política em sistemas democráticos, por si só, já é um fator que caminha lado a lado com a opinião pública, de maneira que busca o respaldo positivo com o eleitorado e a população (SHAPIRO, 2011). Ou seja, a ação política atrela-se e pode moldar a opinião pública de acordo com os rumos que ela toma, principalmente a partir dos interesses que ela atende ou visa atender. A utilização de informações falsas pode modelar de uma maneira mais profunda a opinião pública porque cria uma nova forma de se compreender as ações políticas de determinado governo e grupo de indivíduos, uma vez que torna determinados elementos da realidade velados e, assim, pode conduzir diferentes ações e garantir sua legitimidade por conta das informações difusas que são apresentadas (BERNARDI, COSTA, 2020). Esse é um dos grandes riscos, como o próprio Fórum Econômico Mundial já havia apresentado anos antes - em 2013 -, do 
uso da internet e, com maior ênfase, das redes sociais para estes fins. Assim, entende-se como a opinião pública ainda vem sendo um aspecto de destaque para a democracia dos EUA e pode render grandes debates, como o próprio Robert Dahl (2001) - principal referencial teórico para embasamento do presente artigo - aponta, ponderando sobre a importância da participação efetiva e do entendimento esclarecido, os quais não são separados; na verdade, todos os elementos que ele menciona são interdependentes e consonantes para a construção de uma democracia efetiva e sólida.

\section{CONSIDERAÇÕES FINAIS}

A título de conclusão, alguns apontamentos, questionamentos e possibilidades serão apresentados nesta última seção do trabalho. Foi possível observar a partir da análise teórica e do panorama do caso concreto que democracia, opinião pública e os fatos supracitados nos tópicos anteriores formam uma conjuntura digna de profundo exame. $\mathrm{O}$ artigo se propôs inicialmente a buscar maneiras de construir pontes analíticas a fim de compreender os eventos e desdobramentos que culminaram no resultado do pleito estadunidense no ano de 2020, que não reelegeu o até então presidente Donald Trump. Mas é importante salientar que se apresenta aqui algumas pontes analíticas, como a escolha do teórico Robert Dahl, para a base teórica que sedimentou o estudo, e que, em todo caso, ficam aqui possibilidades de aprofundamento, já que toda a conjuntura que envolve uma eleição, e no caso desta em particular, é extremamente densa e cheia de nuances.

Entre muitos teóricos há um consenso na visão idealizada e romântica que os próprios norteamericanos compartilham da noção da própria democracia e funcionamento das estruturas políticas que os cercam. Em um artigo intitulado "O mito do mandato presidencial" (1990), Dahl consegue apontar uma dessas noções compartilhadas, o entendimento comum que o presidente representa o povo todo de uma maneira única e que a sua eleição lhe outorga um mandato do povo em apoio a sua postura política, o que o autor denomina de "pseudo democratização da presidência". Com base na obra "Interpreting Elections" de Stanley Kelley, Dahl consegue traçar e expor as principais linhas que percorrem a pseudo democratização da presidência estadunidense.

Seu primeiro elemento é a crença de que as eleições contêm mensagens sobre problemas, diretrizes e programas - mensagens claras para todos, e específicas o bastante para serem diretivas (...) para qualificar-se como mandatos, as mensagens sobre diretrizes e programas devem refletir ideias estáveis, tanto de eleitores individualmente como do eleitorado como um todo (...) No eleitorado (...) o consenso geral afirma que vitórias arrasadoras tem mais probabilidade de resultar em mandatos do que as vitórias por pequena margem (KELLEY apud DAHL, 1990, p. $37)$.

Dessa forma, uma questão fundamental pode ser levantada: será que as eleições presidenciais são capazes de revelar a informação de que uma pluralidade ou a maioria dos votantes prefere os 
planos de ação do vencedor e deseja que ele os realize? A vitória de Biden representa que a maioria dos eleitores americanos está de acordo com suas propostas? Kelley rejeita a teoria que ele denomina de "primitiva" de enxergar o papel desempenhado pelas eleições, descrita acima em sua citação. Para ele, as eleições presidenciais servem somente para eleger um presidente, e são as pesquisas de opinião que fornecem as informações acerca das opiniões, atitudes e convicções responsáveis pelo resultado do pleito.

Então o resultado de um processo eleitoral está diretamente relacionado à opinião pública. Uma questão cercada de simbolismos, a opinião pública é parte fundamental do maquinário da comunicação humana. Pode-se defini-la de maneira muito elementar como os "aspectos do mundo exterior que têm a ver com o comportamento de outros seres humanos, na medida em que o comportamento cruza com o nosso, que é dependente do nosso, ou que nos é interessante". É preciso compreender e presumir que tudo o que cada indivíduo faz está baseado não em um conhecimento direto e determinado, mas sim em imagens feitas por ele ou transmitidas a ele (LIPPMANN, 2008). E muito provavelmente o fenômeno que alguns pesquisadores denominam de a "crise da democracia" tenha raiz no fato de que a democracia em sua forma original até então não havia enfrentado seriamente o problema advindo do fato de que a imagem interna na cabeça das pessoas não corresponde automaticamente ao mundo exterior.

*Artigo recebido em 19 de fevereiro de 2021, aprovado em 13 de julho de 2021.

\section{REFERÊNCIAS}

ALONSO, Angela. Repertório, segundo Charles Tilly: História de um conceito. Sociologia \& Antropologia, v. 2, n. 3. 2012, pp. 21-41.

BACCINI, Leonardo; BRODEUR, Abel; WEYMOUTH, Stephen. The COVID-19 Pandemic and the 2020 U.S. Presidential Election. Intitute of Labor Economics, 2020.

BAPTISTA, Renata Ribeiro; AGUIAR, Júlio César de. Fake news, eleições e comportamento. Direito, Estado e Sociedade, v. XX, 2020.

BERNARDI, Ana Julia Bonzanini; COSTA, Andressa Liegi Vieira. Populismo e fake news na era da pós-verdade: comparações entre Estados Unidos, Hungria e Brasil. Cadernos de Campo, n. 28, 2020, p. 385-412.

CASO GEORGE FLOYD: MORTE DE HOMEM NEGRO FILMADO COM POLICIAL BRANCO COM JOELHO EM SEU PESCOÇO CAUSA INDIGNAÇÃO NOS EUA. BBC NEWS, 2020. Disponível em: 〈https://www.bbc.com/portuguese/internacional-52818817>. Acesso em 16 out. 2021. 
DAHL, Robert Alan. Sobre a democracia. Trad. Beatriz Sidou. Brasília: UnB, 2001.

DAHL, Robert Alan. Um prefácio à teoria democrática. Trad. Ruy Jungmann. Rio de Janeiro: Jorge Zahar, 1989.

DAHL, Robert Alan. Poliarquia: Participação e oposição. Trad. Celso Mauro Paciornik. São Paulo: Edusp, 1997.

DAHL, Robert Alan. A Constituição norte-americana é democrática? Trad. Vera Ribeiro. Rev. Mario Brockmann Machado. São Paulo: FGV, 2015.

DAHL, Robert Alan. "The pseudodemocratization of the American Presidency". The Tanner Lectures on Human Values, Harvard University, apr. 1988.

DAHL, Robert Alan. "Os sistemas políticos democráticos nos países avançados: Êxitos e desafios". In: BORON, Atilio A. (org.). Nova hegemonia mundial: Alternativas de mudança e movimentos sociais. Trad. J.C.C.B. Silva. Buenos Aires: CLACSO, 2004, pp. 53-72.

DAHL, Robert Alan. “O mito do mandato presidencial”. Trad. Isa Mara Lando. Lua Nova: Revista de Cultura e Política, n. 24, set. 1991, pp. 27-54.

DAHL, Robert Alan. "Os sistemas políticos democráticos nos países avançados: Êxitos e desafios”. In: BORON, Atilio A. (org.). Nova hegemonia mundial: Alternativas de mudança e movimentos sociais. Trad. J.C.C.B. Silva. Buenos Aires: CLACSO, 2004, pp. 53-72.

ESTUDO MOSTRA EFICIÊNCIA DO ISOLAMENTO SOCIAL CONTRA O NOVO

CORONAVÍRUS. Universidade Estadual do Rio de Janeiro, 11 de maio de 2020. Disponível em: <https://www.uerj.br/noticia/11078/>. Acesso em 16 out. 2021.

FERREIRA et al. A América em primeiro lugar: o discurso de Donald Trump. Le Monde Diplomatique Brasil, Populismo e Crise, 2021.

GONÇALVES, Williams; TEIXEIRA, Tatiana. Trump e a inflexão da Grande Estratégia. Tempo do Mundo, v. 5, n. 1, 2019, p. 177-200.

INATOMI, Celly Cook. Direitos Civis e o Governo Trump: impressões sobre um antagonismo. Tempo do Mundo, v.5, n.1, 2019, p. 67-106.

LEE, Terry. The global rise of "fake news" and the threat to democratic elections in the USA. Public Administration and Policy, v. 22, n. 1, 2019, p. 15-24.

LIPPMANN, Walter. "Public Opinion”, New York, Harcourt Brace, 1922.

LOWI, THEODORE \& CALISE, Mauro. Hyperpolitics an interactive dictionary of politic. The University of Chicago Press, Ltd., London, 2010.

MORAIS, Jennifer Azambuja de; COSTA, Andressa Liegi Vieira; BERNARDI, Ana Julia Bonzanini. Populismo, polarização política e a pandemia do coronavírus: Donald Trump e a opinião pública nos Estados Unidos. Debates, Porto Alegre, v. 14, n. 3, 2020, p. 126-149.

OLIVER, J. Eric; RAHN, Wendy M. Rise of Trumpenvolk: Populism in the 2016 election. The Annals of American Academy, 2016. 
PECEQUILO, Cristina S.; MAGNOTA, Fernanda. A eleição nos EUA e seus desdobramentos para o Brasil. 2020. Disponível em: 〈https://www.youtube.com/watch?v=re_UdcfbNOQ\&t=1412s>. Acesso em 16 out. 2021.

SCHATTSCHENEIDER, E. Elmer. The Semisovereign People, New York, Rinehart and Winston, 1960.

SHAPIRO, Robert. Public Opinion and American Democracy. Public Opinion Quaterly, v. 75, n. 5, 2011, p. 982-1017.

TILly, Charles. Movimentos Sociais como Política. Revista Brasileira de Ciência Política, n. 3. Brasília, janeiro-julho de 2010, pp. 133-160.

TILLY, Charles. Social movements and (all sorts of) other political interactions - local, national, and international - including identities. Theory and Society, v. 27. 1998, p. 453480.

TILLY, Charles. Social Movements as Historically Specific Clusters of Political Performances. Berkeley Journal of Sociology, v. 38. 1993-1994, p. 1-30.

VINHA, Luís da. Previsivelmente incoerente: Uma análise preliminar da política externa de Donald Trump. Relações Internacionais, Lisboa, n. 55, p. 09-33, set. 2017. 